\section{NODRIVERS REQUIRED}

Automation is one of the hottest topics in transportation research and could yield completely driverless cars in less than a decade.

\section{BY M. MITCHELL WALDROP}

his summer, people will cruise through the streets of Greenwich, UK, in electric
shuttles with no ones hands on the steershuttles with no ones hands on the steer-
ing wheel - or any steering wheel at all. ect, part of a larger study of driverless cars funded by the UK government, is just one of many efforts that seek to revolutionize transpor-
tation. Spurred in part by a desire to end the catation. Spurred in part by a desire to end the car-
nage from road accidents - about $90 \%$ of which are caused by driver error - the race is on to never doze at the wheel, get distracted by text messages or down too many pints at the pub.
Almost every major car maker is working on some form of automation, as are many electronics companies. But looming over everyone
is the Internet giant Google: the company has in driverless-car research since October 2010, when it announced that it had entered the field
year earlier - and that its driverless test vehicl had already logged more than 200,000 kilome-
tres on roads near its headquarters in Mou tain View, California, and elsewhere in the state. lation glvanized cor makers and governm research-funding agencies around the world to accelerate their efforts in this arena.

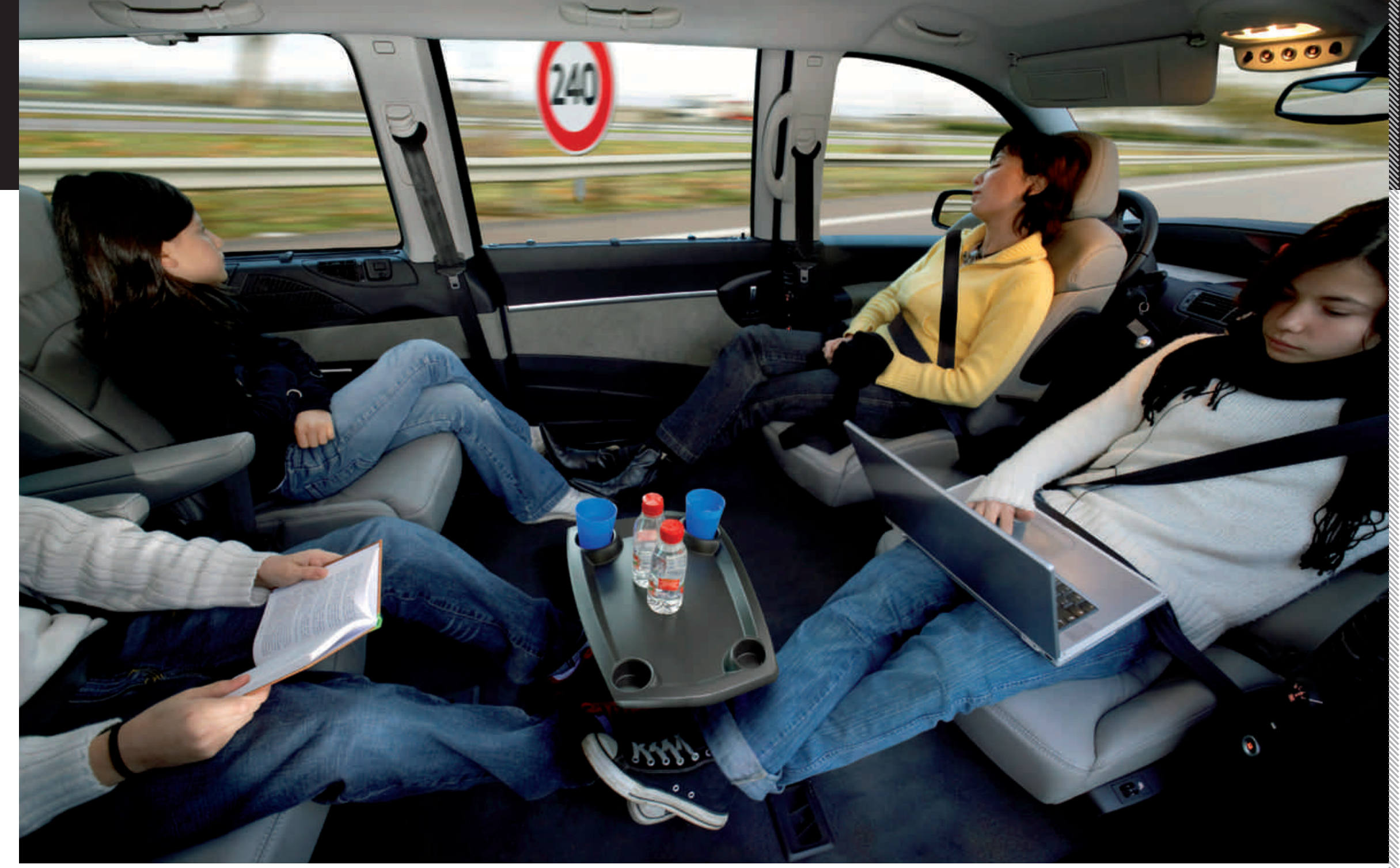

"I've never seen anything move so quickly to expand those maps as part of the company's from concept into products," says Richard
Bishop, an automotive consultant who headed efforts to photograph the world's road-
ways for Google Maps, says Sebastian Thrun, an Bishop, an automotive consultant who headed
a US Department of Transportation research Google Maps, says Sebastian Thrun, an
engineer who founded the Google car project programme on automated motorways in the and ran it until 2013. remain, developers say they can see clear paths $\quad \begin{gathered}\text { A tougher problem, says whe car how to respond to what he calls "the } \\ \text { the }\end{gathered}$ for solving most or all of them. long tail of unlikely events". Early on, he says, At Google, for example, most of the driver- the Google team developed algorithms for less-car work so far has been carried out using handling frequent, obvious challenges such Positioning System receivers and mappingtech- as the cars drove for thousands of kilometres nology along with radar to detect obstacles, a they recorded oddball events such as a plastic laser ranging system to scan the surroundings in bag blowing across the motorway or a couch three dimensions, and video cameras to identify sitting in the middle of the road. "There were objects such as trafficlights, construction signs, many more of those than we believed in the driverless cars') The on-board computer o de such rare events has been to way to hanwith processing power equivalent to several de such arise devise responses with the help of desktop units - integrates all the information high-powered machine-learning algorithms and decides how the car should behave in any and then test those solutions with simulations given situation. Tolessen the load on the driving and yet more driving.

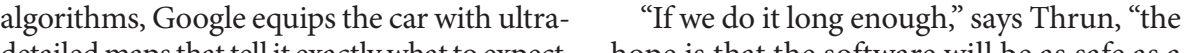
down to the heirht of every curb. Sceptics point out that this mapping require- How long that will take remains an open quesment restricts the car to places that have already tion. Google has publicly estimated about five been surveved to that level of precision, such as years - but the company is currently not grantMountain View. But it would be relatively easy ing interviews about its project.
Additional safety could come from equipping basic safety message: position, speed, direction cars and trucks with Wi-Fi-like vehicle-to-vehicle (V2V) radios, which would allow them to Peloton Technology, a start-up firm in Menlo as a car running through a red light. That would ize V2V technology for heavy trucks. But that give both driverless and human-operated vehi- will be enough to eliminate many accidents, he cles time to steer clear. will be enough to eliminate many accidents, he says. Then there are the energy efficiencies -
not just from platooning, he says, but from cars working together to minimize stop-and-go traincorporated into driverless vehicles, it has been developed largely through separate efforts. Th concept has already been road-tested as part
of the European Union's Safe Road Trains for also wher fuel efficiency is dismal. If the cars can to prevailing traffic density - a practice somethe Environment project, in which lines of cas like ducklings tailing their mother. These road trains, or platoons, avoid catastrophic pile-ups
because the V2V signals cues every car to hit the brakes at the same instant as the truck. And because of erodmaniss the road trins Aved at least $10 \%$ in fuel consumption.

Such experiments have piqued the interest of the car maker General Motors, which last September announced it will support $V 2 V$ technofewinthe Highway Traffic Safety Administration islooking to issue regulations requiring $\mathrm{V} 2 \mathrm{~V}$ radiosin ing to issue regulations requiring
all new $U$ US "The vehicles would just be broadcasting tem might be able to minimi the need to stop at all.

Ultimately, the timescale for deploying these much bro cost? Who will own them - individuls service companies that provide transportation driverless car gets into an accident? And will people accept and trust them? Such questionscan only be answered through exprience. And given the pace of inno Nature in Washington DC M. Mitchell Waldrop is a features editor for

\section{DITCH THE DRIVER}

ก) mil|inn traffic fatalities every year worldwide

\section{$90 \%$}

of all accidents are due to driver error

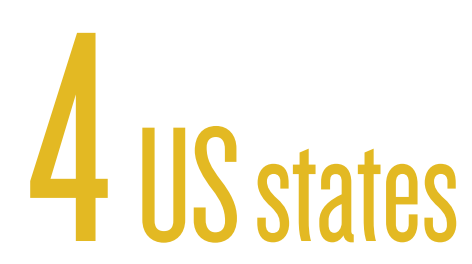

and the District of

Columbia have passed laws to allow driverless cars on their roads

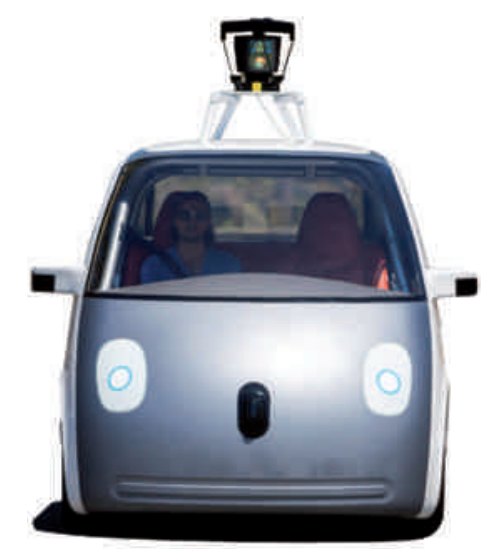




\section{A world of driverless cars \\ .}

have thought a few years ago, with many experts predicting tha questions remain, but it is already possible to imagine how this new world of driverless cars will work.

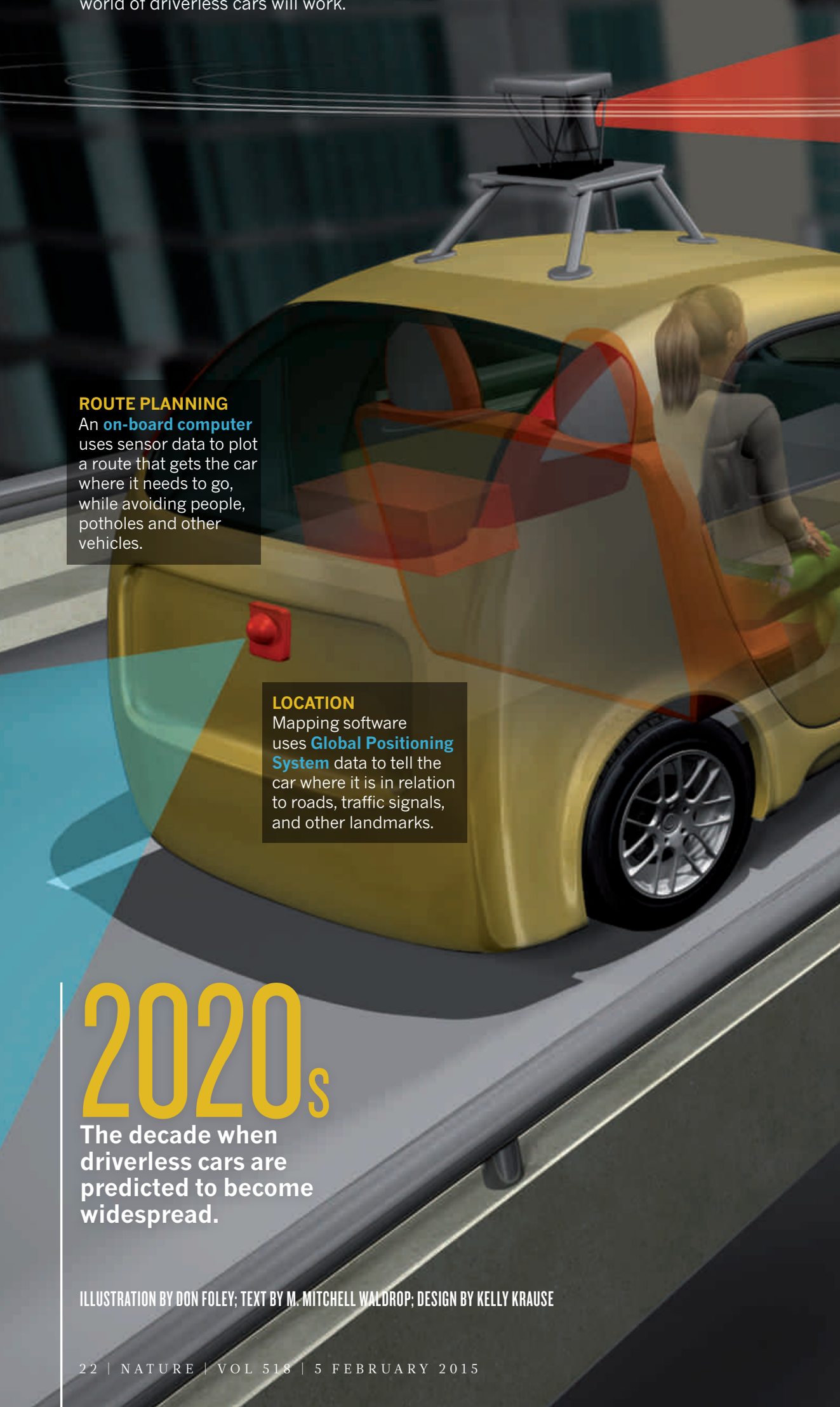

